Western University

Scholarship@Western

Education Publications

Education Faculty

7-16-2018

\title{
An Emotional Skills Intervention for Elementary Children with Autism in China: A Pilot Study
}

Gabrielle Lee

glee329@uwo.ca

Sheng Xu

University of Chongqing

Hua Feng

National Changhua University of Education

Gloria Lee

Michigan State University

Shaoju Jin

Sichuan University

See next page for additional authors

Follow this and additional works at: https://ir.lib.uwo.ca/edupub

Part of the Education Commons

Citation of this paper:

Lee, Gabrielle; Xu, Sheng; Feng, Hua; Lee, Gloria; Jin, Shaoju; Li, Dan; and Zhu, Shuangshuang, "An Emotional Skills Intervention for Elementary Children with Autism in China: A Pilot Study" (2018). Education Publications. 142.

https://ir.lib.uwo.ca/edupub/142 
Authors

Gabrielle Lee, Sheng Xu, Hua Feng, Gloria Lee, Shaoju Jin, Dan Li, and Shuangshuang Zhu 
An Emotional Skills Intervention for Elementary Children with Autism in China: A Pilot Study 


\begin{abstract}
The purpose of this pilot study was to examine the effects of an emotional skills intervention on behavioral and emotional competence, as well as on communication for children with autism in China. Eight children (seven boys and one girl), aged 7 to 8, participated in this study. We used a pre and posttest group design. The intervention consisted of 10 group sessions and four individual sessions. Each group session had two or three children. The intervention curriculum consisted of emotion recognition, emotion recognition within context, self-expression of emotions, seeking help when encountering problems, and techniques for emotion regulation. Results indicated that the intervention significantly improved children's emotional skills, behavioral and emotional competence, and communication. The potential implications of this study for elementary children with autism in China are also discussed.

Keywords: emotional skills intervention, cognitive behavior therapy, behavior analysis, elementary children, autism, China
\end{abstract}


An Emotional Skills Intervention for Elementary Children with Autism in China: A Pilot Study

\section{Introduction}

The core deficits of autism spectrum disorder (ASD) are social communication difficulties and restrictive/repetitive patterns of movements, interests, and activities (American Psychiatric Association, 2013). Young children with ASD often misunderstand what is considered appropriate social interactions with others, and their restrictive/repetitive patterns in behavior or activities further limit their ability to effectively communicate with others in social situations. Many young children with ASD may develop maladaptive behavior as a means to communicate their needs and wants. As they grow up and encounter more complex social situations, children with ASD tend to feel socially isolated in school (Bauminger \& Kasari, 2000; Nirit Bauminger, Shulman, \& Agam, 2003), are subject to relatively high levels of distress in social situations (Tantam, 2003), and are more susceptible to the risk of developing anxiety or other comorbid mental disorders (Simonoff et al., 2008).

Emotion regulation, as defined by Gross (2002), is the process of how individuals experience and express emotions, including how individuals modify and change the experienced emotions. The underlying mechanisms of emotions regulation in children with ASD are largely under-explored, but their poor emotion regulation is related to core deficits of ASD (Samson et al., 2014; Samson, Huber, \& Gross, 2012). Poor emotion regulation in children with ASD is usually demonstrated by their problem behaviors, such as tantrums, aggression, self-injurious behaviors, inadequate school engagement and peer relationships (Jahromi, Bryce, \& Swanson, 2013; Jahromi, Meek, \& Ober-Reynolds, 2012; Mazefsky \& White, 2014), possibly due to a lack of adaptive regulatory strategies (Lang, Regester, Lauderdale, Ashbaugh, \& Haring, 2010; Samson et al., 2012). Difficulties in emotion regulation may also be aggravated by inherent 
deficits in social communication (Jahromi et al., 2013, 2012; Mazefsky et al., 2013; Mazefsky \& White, 2014). Additionally, children with ASD may have an insufficient understanding of their own and others' emotions (Rieffe, Terwogt, \& Kotronopoulou, 2006), and they do not accurately label emotions and recognize important contextual cues in relation to people's emotions (Moyal, Henik, \& Anholt, 2014). Thus, these children tend to have difficulties recognizing and describing emotions. The lack of one or more of these skills presents a barrier to problem-solving in situations where these children experience negative emotions. Evidence from the literature suggests emotion regulation in children with ASD is multi-faceted, as it relates to their lack of awareness of people's emotions and associated contextual cues, effective communicative skills to convey their emotions, and practical skills such as coping and problem solving (Compas et al., 2014; Weiss, Thomson, \& Chan, 2014). Therefore, it is important to develop a comprehensive intervention to improve emotion regulation for children with ASD.

Cognitive behavioral therapy (CBT) is effective in treating emotional impairments (e.g., anxiety, anger) and improving emotion regulation in individuals with high-functioning ASD (Ho, Stephenson, \& Carter, 2013; Lang et al., 2010; Ung, Selles, Small, \& Storch, 2015). Interventions using cognitive-behavioral approaches to teach or improve social skills are recommended evidence-based practices for school-aged students with ASD (National Autism Center, 2015; Wong et al., 2015). Although components of intervention varied across studies, most CBT programs include the recognition of emotions in people, describing the context in relation to emotions, cognitive restructuring, social skills, problem solving strategies, and coping skills or techniques. Sessions are taught with visual supports, social stories, role play, hands-on activities, and worksheets. The CBT approach focuses on changing thoughts resulting in behavioral change to address negative emotions. It is also modified and adapted to suit the 
particular needs for adults, children, and young children with ASD (e.g., Attwood, 2004; Scarpa, Wells, \& Attwood, 2013). For example, Scarpa and Reyes (2011) first evaluated the efficacy of a CBT program in young children (ages 5 to 7) diagnosed with high-functioning ASD. They found that the children who received the CBT treatment demonstrated improved knowledge of emotions and ability to regulate their anxiety and anger. The CBT program treatment in Scarpa and Reyes (2011) was adapted with activities and discussion at a developmentally appropriate level for young children. They used common social situations in which young children with ASD typically experienced anxiety and anger. They also provided visual supports (e.g., pictures, scripts) and opportunities for practices to facilitate children's learning.

Besides modifying the content to be developmentally appropriate, most CBT programs incorporate instructional strategies of applied behavior analysis (ABA) when working with individuals with ASD, such as assistive prompts and token economies (Lang et al., 2010). For example, Thomson, Riosa, and Weiss (2015) employed a CBT-based emotion regulation intervention for children with ASD with a token economy to promote and maintain motivation for children in the program. The parents reported a significant improvement in overall emotion regulation for their children, and the children reported decreased emotion dysfunction. Incorporating the ABA strategies is important for successful implementation of the intervention programs. Despite its success, CBT-based interventions have not been adapted to Chinese culture and evaluated for Chinese children with ASD.

Behaviorally-based social skills training primarily focuses on either teaching appropriate responding, maintaining, and initiating social interactions, or receptive and expressive communication skills in a group or one-on-one format for individuals with ASD (Camargo et al., 2015; Matson, Matson, \& Rivet, 2007; Reichow \& Volkmar, 2009; Virués-Ortega, 2010). 
Typically, the instructional strategies involve modeling, assistive prompts, visual supports, and positive reinforcement. Social skills encompass a wide array of abilities that sometimes include emotional competence. For example, Feng, Lo, Tsai, and Cartledge (2008) utilized a cognitivebehavioral approach to teach emotion-related skills to a sixth-grade student with ASD. The target emotional skills included desire-based emotion recognition, expression of one's own emotions, anger control, and identification of others' beliefs. They reported that the student's appropriate social interactions with peers in school increased after the training, indicating that improved emotional skills facilitated or enhanced social competence. Additionally, their study was conducted in Taiwan, a Mandarin-speaking country, suggesting the cross-cultural applicability of evidence-based practices developed in the western culture.

The prevalence of ASD in China is estimated as $1 \%$ of the total population (Sun et al., 2013). This translates into approximately 13 million people with ASD in China. However, available ASD services across mainland China are so sparse that most families of members with ASD do not have access to adequate services (Huang, Jia, \& Wheeler, 2013; Liu et al., 2011). Additionally, the available ASD services are exclusively provided to children under the age of 6 before they enter elementary school. Services for school age children and adolescents are almost absent (McCabe, 2013). Recent surveys indicate that $13.2 \%$ to 55.2\% of children with ASD are enrolled in general education schools in China (Liu, 2007; Shenzhen Autism Society, 2013; Wang, Peng, \& Wang, 2011), but the government does not mandate that these students receive individualized and appropriate education (Huang et al., 2013). As a result, students with ASD continue to encounter emotional and behavioral difficulties without adequate assistance. It is the priority of Chinese researchers to develop or adapt an evidence-based intervention and evaluate the intervention for these students in order to meet their needs. 
Although research indicates that CBT-based interventions for children with ASD are effective in improving their emotional management skills, such interventions are not evaluated in Chinese culture. In response to the research gap and the practical need, this study was the first intervention study addressing emotion-related skills for elementary students with ASD in mainland China. The purpose of this study was to pilot test the efficacy of an emotional skills intervention by examining its effects on behavioral and emotional competence and communication. The research hypotheses were as follows:

1) Compared to the pretest, children's behavioral and emotional competence increased after receiving the intervention;

2) Compared to the pretest, children's communication improved after the intervention.

\section{Method}

\section{Participants}

Eight children with ASD (seven boys, one girl), age 7 to $8(M=7.69 ; S D=0.56)$, participated in the study. All of the participants attended public elementary schools in general education classrooms in China and did not receive any special education services in schools or mental health services in the community. They were recruited through the website of a university-affiliated autism research center and support groups for families of children with ASD in that area. The inclusion criteria included (a) the child was between 6 and 9 years old, (b) the child had an official diagnosis of ASD, (c) the child had an overall IQ above 70, and (d) the child's parents or teachers reported behavioral and emotional problems. The child was excluded from the study if s/he had a chronic medical condition, such as seizures. All eight children were diagnosed as having mild to moderate ASD with no other comorbid mental disorders. Three 
children had a mild intellectual disability with an overall IQ between 70 and 75. See Table 1 for parent demographic information and child characteristics.

Insert Table 1 here

\section{Procedure}

The study was conducted in a university-affiliated autism center of a major city located in central China. All intervention sessions were delivered in Mandarin. All sessions were delivered either as group or individual sessions. All group sessions were conducted in a group room $(3.5 \mathrm{~m}$ $\mathrm{x} 4 \mathrm{~m} \times 3 \mathrm{~m}$ by size) with the presence of two or three children, an instructor, and one or two assistants in the room. The children sat on chairs facing the instructor, and the assistant(s) sat behind two children. Individual sessions were conducted in the therapy rooms. Each individual room was approximately $2.5 \mathrm{~m} \times 2.5 \mathrm{~m} \times 3 \mathrm{~m}$ by size. The instructor and the child sat facing each other. A video camera was set on a tripod on the side of the rooms during the sessions.

The study used a pre- and post-test design. Parents self-reported their demographic information and completed child assessments at entry prior to the beginning of intervention. After completion of all entry assessments, two or three children formed a group and received the intervention sessions in a small-group format once per week for 10 weeks. Each child also received four individual sessions following the 10th group session. A total of three small groups were formed based on the time and order of their enrollment for the study. All three groups received the intervention independently of one another, with sample sizes of 3,3 , and 2 , respectively. The post intervention assessments were conducted one week following the completion of the intervention. 
A brief probe containing 15 questions on target emotional skills for each lesson was conducted before and after each session to assess each child's learning. If a child had inaccurate responses over $80 \%$ of the questions during a pre-session probe, the instructor would assign a teaching assistant to provide additional assistance during the session. The assistance consisted of providing specified prompts (described in the Intervention section) for correct responses when the instructor asked questions, reminding the student to attend to the instructor and other children, and delivering tokens to the child to maintain participation. The same questions were probed after the session was completed. During pre and post session probes, the instructor provided social praise and feedback based on the child's attending and cooperative behavior regardless of the accuracy in their responses.

Parents observed from a two-way mirror during each session and participated in an individual 10 to 15 min debrief upon completion. One of the instructors met with the parent, with the presence of the child, to briefly go over the lesson and homework. The parents were encouraged to discuss their child's challenges with the instructors and ask questions about the lessons or homework during this time.

\section{Curriculum Development}

The adaptation of the curriculum was primarily based on the suggested topics in Attwood (2004), Scarpa et al. (2011) and McKay, Wood, and Brantley (2007), with content adapted for Chinese culture as suggested in Feng, Chou, Sun, and Lee (2014). We used teaching strategies derived from the ABA principles when delivering the content of the materials, including choral responding, response cards (Heward, 1994), discrete trials instruction, prompt hierarchies, time delay, and multiple instances of exemplar instruction. 
The intervention consisted of a total of 14 sessions, including 10 group sessions and four individual sessions. The first 10 group sessions consisted of: a) three sessions on recognition of basic emotions (i.e., happy, sad, scared, angry, and surprised), b) three sessions on identifying others' emotions in context, c) three sessions on expressing their own emotions in context, and d) one session on identifying situations where seeking help is necessary and how to seek help. The four individual sessions included: a) one session on seeking help and b) three sessions on selecting and practicing techniques of relaxation (e.g., deep breathing), distraction (e.g., counting) and self-affirmation when negative emotions arose. See Table 2 and 3 for examples used for target skills in sessions. All examples used in group sessions of the study were common scenarios for elementary-aged children in China, and the scenarios used in individual sessions were provided by parents and tailored specifically for each child.

Each session also included a brief homework assignment the child could complete either by him/herself or with assistance from their parents. Homework for sessions 1 to 3 consisted of a picture of a blank face, where the child was instructed to draw one facial expression of their choice. A diary of feelings and emotions was assigned as homework for sessions 4 to 7 and session 9. The children could write or draw an event and its associated emotion that happened to them that week. The homework for session 8 contained five scenarios, and the children were asked to describe the emotions based on each scenario. In the homework of sessions 10 to 13 , the children were asked to draw or write one event associated with anger, one event of sadness, and one event of fear. They were also instructed to describe and practice their proposed actions in response to each negative emotion resulting from an event. Session 14's homework consisted of six scenarios, and the children were instructed to describe their own negative emotions (e.g., 
"How do you feel?), propose possible actions (e.g., What can you do about it?), and provide selfaffirmation (e.g., What can you say to encourage yourself?).

Insert Tables 2 and 3 Here

The four individual sessions focused on in-vivo role play experiences of scenarios with the instructor, practices of emotion regulation techniques based on the in-vivo experiences, as well as self-delivery of acceptance, affirmation, and encouragement statements (e.g., "I am a good kid with emotions, and I am learning to manage my emotions"). The self-acceptance component was based on suggestions in McKay et al. (2007), the cultural adaptation recommended in Feng et al (2014), and was confirmed through informal interviews with the parents. For example, parents reported that they instructed their children that boys should never cry and it was bad to get angry or show negative emotions. We also observed that some of the children made negative comments about themselves (e.g., "I'm so stupid!” "I'm bad!”). Thus, we tailored the self-affirmation statements for each child.

\section{Intervention}

Three graduate students rotated the roles of the instructor and the teaching assistant during instruction. Each 50-min group session contained a 5-min introduction, a 15-min discussion, a 20-min crafts or role play activities, and a 10-min wrap-up. Materials used for instruction included picture cards and video clips showing examples of emotions in various contexts commonly observed in home or schools for elementary-aged children. Three to five examples of each emotion in different contexts were presented during sessions. Some scenarios were obtained from parental reports on situations that their children typically felt happy, sad, 
scared, angry, and surprised. The instructor used choral responding, response cards (Heward, 1994), and discrete trials instruction during group sessions. Each child received immediate and specific feedback (i.e., reinforcement for correct responses and prompts for incorrect responses) from the instructor. Visual cues, such as pictures or text, were used in the beginning but removed once one of the children could provide correct responses as a model to the group. If a child failed to provide accurate responses, the teaching assistant provided assistance based on a predetermined hierarchy (e.g., echoic prompts for verbal responses, gestural prompts for selectionbased responses, physical guidance, if necessary). The prompts were removed once the child independently provided accurate responses to the instruction. A 3-s time delay was incorporated in the discrete trial instruction to increase independent responses. A token economy was implemented by the instructor or teaching assistant(s) to maintain attending behavior and active participation during sessions. The children had an opportunity to use tokens to exchange for their preferred items or activities after each session ended.

The instructor used the same strategies during individual sessions. Individual sessions contained a 5-min introduction, a 5-min discussion of homework, a 20-min role play on the implementation of techniques and self-affirmation in different scenarios, and a 10-min wrap-up. The scenarios used in role play and practices were selected from each child's homework or reported by the parent from an informal interview on situations where the child tended to have emotional difficulties.

\section{Treatment Fidelity}

All children in three groups received the same intervention. All three instructors were trained to deliver the intervention to at least one individual case prior to the study. All sessions were supervised by a professor of special education and a clinical psychologist with a behavior 
analyst credential. Treatment fidelity was obtained in $62 \%$ of the sessions that were randomly selected from each unit of intervention, evenly distributed across three groups for group sessions, and across all children for individual sessions. The treatment fidelity was independently assessed from recorded videotapes by either a trained graduate student or the supervising faculty using the fidelity checklist. The treatment fidelity ranged from $85 \%$ to $100 \%$ for the first group $(M=$ $91.82, S D=6.66), 86 \%$ to $100 \%$ for the second group $(M=94.82, S D=6.08)$, and $86 \%$ to $100 \%$ for the third group $(M=95.1, S D=5.93)$.

\section{Measures}

Diagnostic measures. All children were diagnosed with ASD with the Chinese version of the Childhood Autism Rating Scale (CARS-Chinese; Li, Zhong, Cai, Chen, \& Zhou, 2005; Lu, Yang, Shu, \& Su, 2004; Schopler, Reichler, \& Renner, 2002) and met the criteria of ASD in the Diagnostic and Statistical Manual of Mental Disorders, 5th Edition (DSM-5; American Psychiatric Association, 2013). All children also underwent the Chinese version of The Wechsler Intelligence Scale for Children-fourth edition (WISC-IV-Chinese; Wechsler, 2003; Zhang, 2008) to assess their IQ level.

The CARS is a behavioral rating scale used in the diagnosis of autism in children above 2 years old (Schopler et al., 2002). It is also used to distinguish diagnoses between autism and other developmental disabilities (Chlebowski, Green, Barton, \& Fein, 2010). The psychometric properties of the CARS-Chinese in Chinese samples include a reliability coefficient of 0.74 and the predictive validity coefficients of 0.5 with the Chinese version of Autism Behavior Checklist (Li et al., 2005; Lu et al., 2004). The CARS rates each item of autism symptoms with scores from 1 to 4 (normal, mildly abnormal, moderately abnormal, and severely abnormal). A total 
CARS score of more than 36 indicates severe autism, 30 to 36 indicates mild to moderate autism, and lower than 30 indicates no autism symptoms.

The children's IQ was assessed from the WISC-IV-Chinese, a psychometric measure of intelligence for children from 6 to 16 years old. The WISC-IV-Chinese has identical contents and most test items as its English version, with revisions on verbal subtests due to cultural differences. The WISC-IV-Chinese has good psychometric properties in Chinese children. The average reliability coefficients ranged from .87 to .97 for composites and .78 to .92 for core subtests, and the concurrent validity coefficients ranged from .60 to .74 with the subtests in the Wechsler Intelligence Scale for Children-Revised-Chinese Version (Zhang, 2009).

Outcome measures. The outcome measures included the emotional skills assessment (developed by the researchers as a measure for children's learning achievement) and two parentrated standardized assessments. The two standardized assessments were the Behavioral and Emotional Rating Scale-Chinese version (BERS-Chinese; Epstein, 2000; Yang, 2001) and the Vineland Adaptive Behavior Scale-Chinese version (VABS-Chinese; Sparrow, Balla, \& Cicchetti, 1984; Wu, Chang, Lu, \& Chiu, 2004).

The items in the emotional skills assessment assessed the target skills of the intervention but with different examples and context. These assessment items were not used during intervention sessions or pre-and post-session probes. The following eight items were assessed: (Items 1 and 2) receptive and expressive labeling of five basic emotions; (Item 3) expressive labeling of five emotions in context; (Item 4) expression of one's own five emotions in context; (Item 5) describing the events causing others' emotions; (Item 6) describing events causing one's own emotions; (Item 7) seeking help in a scenario; (Item 8) showing at least two techniques to regulate negative emotions. The total possible scores ranged from 0 to 16 . The score for each 
item was based on responses to the questions within each item. A score of " 0 " was assigned when the child provided incorrect answers or had no response to the questions within one item. If the child provided accurate answers to some questions but not all questions within one test item, "1" was scored. The maximum score, "2" was assigned if the child provided accurate answers to all questions within one item. Examples of scenarios used in the assessment were similar but different from those presented in the intervention shown in Table 2 and 3.

The BERS-Chinese (Epstein, 2000; Yang, 2001) is a strength-based measure to assess children's (ages 6 to 18) behavioral and emotional strengths and competencies. The BERS was administered to the parents at entry and after the intervention was completed. It has 52-items with a 4-point Likert scale $(0=$ not at all like, $1=$ not much like, $2=$ like, and $3=$ very much like) to measures a child's strength in interpersonal relationships (ability to interact with others), family involvement (relationships with family), intrapersonal relationships (perception of his/her accomplishments), school functioning (competence in school), and affective strength (ability to give and receive affection). The BERS-Chinese has good psychometric properties (internal consistency $\alpha=.80$, test-retest reliability range between .73 and .88 ) in Chinese youth population (Yang, 2001). The total strength quotient over 90, or the standard scores in subscales over 8 indicate no behavioral and emotional disturbance. The strength quotient between 80 and 90, or scores in subscales between 6 to 7 indicate borderline behavioral and emotional disturbance. A strength quotient lower than 80, or the scores in subscales lower than 6 indicate at-risk of behavioral and emotional disturbance. In our study sample, the internal consistency was excellent for the total strength index $(\alpha=.91)$, good for interpersonal strength $(\alpha=.85)$, 
intrapersonal strength $(\alpha=.83)$, and affective $(\alpha=.82)$, and acceptable for school functioning $(\alpha$ $=.73)$ and family involvement $(\alpha=.70)$.

The VABS-Chinese (Sparrow et al., 1984; Wu et al., 2004) measures levels of adaptive functioning from birth to adulthood. The VABS is also widely used for individuals with ASD (Carter et al., 1998). The VABS-Chinese was administered to the parents before and after the intervention. It is a 242-item, 5-point Likert scale $(0=$ never, $1=$ rarely, $2=$ sometimes, $3=$ often, and $4=$ almost always) standardized assessment that measures adaptive behaviors in the domains of communication (receptive, expressive, and written communication), daily living skills (personal, domestic, and community), socialization (interpersonal relationships, play and leisure time, and coping skills), and motor skills (find and gross motor). The VABS-Chinese has the construct validity coefficients ranging from .44 to .97 and the split-half reliability coefficients from .66 to .99 in all scales (Wu et al., 2004). The reliabilities for each of the four domains were $.96, .95, .96, .86$, and .99 in communication, daily living skills, socialization, motor skills, and the total adaptive score, respectively, in our study sample.

Social validity survey. Social validity in regards to feasibility, acceptability, perceived helpfulness, and satisfaction of the intervention was measured after the completion of the intervention through a parent-reported survey questionnaire developed by the researchers. Of the total 31 items in the questionnaire, items 1 to 6 pertained to intervention acceptability (content, activities, needs, group format, individual format, and cultural aspect), items 7 to 12 measured feasibility (time periods, locations, instructors, financial burdens, commuting), items 13 to 17 assessed satisfaction in the areas of children's communication, emotional management, problem solving, problem behaviors, and emotional outbursts. Items 18 to 30 evaluated parental perceived helpfulness in the target skills of intervention pertaining to social and emotional communication 
(e.g., emotion recognition, expression, communication, seeking help). Each item was rated on a 5-point Likert scale ( $1=$ not satisfied or not helpful to $5=$ very satisfied or very helpful). The last question was an open-ended question inviting parents to provide suggestions or share experiences of the intervention. Besides the survey, we also used the participant retention rate and the homework completion rate as a measure for social validity of the intervention.

\section{Data Analysis}

Due to the small sample size, we used non-parametric statistical techniques to analyze the data. We used the Wilcoxon signed rank tests to compare scores on pre and posttests. We calculated the Cohen's $d$ effect sizes using the formula $\mathrm{d}=\left(\mathrm{M}_{\text {diff }} / \mathrm{SD}_{\text {average }}\right) / \sqrt{2(1-\mathrm{r})}$ with the consideration of dependence between pre and post-tests corrected (Morris \& DeShon, 2002). In the formula, $\mathrm{M}_{\mathrm{diff}}$ is the pretest-posttest mean difference, $\mathrm{SD}_{\text {average }}$ is the average of SDs of pre and posttests, and $\mathrm{r}$ is the pretest-posttest Spearman's rho correlation. An effect size of 0.2 indicates a small effect, 0.5 a moderate effect. 0.8 a large effect (Cohen, 1988).

\section{Results}

The result of the Wilcoxon signed rank test indicated the children's total scores (range: 016 on the emotional skills assessment as rated by clinicians) increased significantly from the preassessment to the post-assessment $(Z=-2.53, p=.011)$. The effect size was large $(d=4.55)$ with a correlation of 0.76 between pre and posttests. The pretest scores ranged from 1 to $11(M=4.88$, $S D=3.52)$, the posttest scores ranged from 10 to $16(M=13.5, S D=1.93)$ for all children in the study.

Table 4 displays the results of Wilcoxon signed rank tests and Cohen's $d$ effect sizes of BERS-Chinese on the behavioral and emotional strengths and competencies rated by the parents. A significant increase from the pre-test to post-test was found in the participant's total standard 
score $(Z=-2.10, p=.04)$, a standardized index of their behavioral and emotional competencies. Among the five subscales measured by the BERS-Chinese, two showed significant improvement, namely in the areas of Intrapersonal Strength $(Z=-2.06, p=.04)$ and School Functioning $(Z=-2.23, p=.03)$, before and after the intervention. The effect sizes for the total Strength Index, Intrapersonal Strength, and School Functioning were .96, 1.11 and 1.13, respectively, indicating a large effect size. Other subscales, namely, Family Involvement $(Z=-$ $1.69, p=.09)$, and Affective Strength $(Z=-1.49, p=.14)$ were reported with a moderate effect size ( $d=.69$, and .58 , respectively), and the Interpersonal Strength had an effect size close to moderate $(Z=-.95, p=.34, d=.42)$.

Insert Table 4 here

The lower panel of Table 4 lists the change in scores and Cohen's $d$ effects sizes of VABS-Chinese in measuring the various adaptive behaviors, as reported by the parents. There was a significant increase in the Communication Domain $(Z=-2.37, p=.02)$ but not in the Daily Living $(Z=-.77, p=.44)$, Socialization $(Z=-1.61, p=.11)$, Motor Skills $(Z=-1.16, p=.25)$, or the Adaptive Behavior Composite Score $(Z=-1.58, p=.12)$. The effect sizes ranged from large to moderate in all scales, with 1.07 in Communication, 0.47 in Daily Living Skills, 0.56 in Socialization, .45 in Motor Skills, and 0.63 in the total Adaptive Composite Score.

The average ratings for the parent-reported survey were $4.71(S D=.42)$ on intervention acceptability, $4.06(S D=.49)$ on feasibility, $4(S D=.45)$ on satisfaction, and $3.8(S D=.38)$ on perceived helpfulness for their child's social and emotional behaviors. The retention rate for this 
study was $100 \%$ for all of the children and parents who participated in the study. The children's weekly homework also had a 100\% completion rate with assistance from their parents.

\section{Discussion}

This was the first study to provide preliminary evidence on the intervention targeting emotion-related skills for Chinese elementary children with ASD in response to the absence of empirically validated intervention in China. The results indicated that the children's emotional skills, behavioral and emotional competence, and adaptive functioning in communication were significantly improved after the intervention. The results of the parent-reported survey indicated a high level of acceptability, feasibility, satisfaction, and parent-perceived helpfulness on the intervention their children received.

The intervention addressed the emotional and behavioral competence for children with ASD in various situations. The acquisition of emotional skills was evident from the results of direct testing in the clinical setting. The results of BERS-Chinese indicated a significant overall improvement in the children's total behavioral and emotional strength and in the subscales of intrapersonal strength and school functioning. The subscales of family involvement and affective strength both had moderate effect sizes, while the interpersonal strength was short of a moderate effect size, even though statistical significance was not reached. The findings were consistent with previous studies, where children's emotion regulation skills improved after receiving the CBT interventions (Scarpa \& Reyes, 2011; Thomson et al., 2015). Further, Scarpa and Reyes (2011) found that the parents rated their children with a significantly higher level of confidence to handle negative emotions after intervention, similar to the increased intrapersonal strength measured by BERS. The intervention implemented in this study consisted of similar curricular components as in Scarpa and Reyes (2011), with the exception that this study did not teach the 
children to utilize cognitive reappraisal to modify their thoughts for behavior change. Instead, the intervention incorporated ABA strategies to teach specific emotional skills for each individual resulting in behavior change measured by direct and indirect assessments of the outcome behaviors.

Results of VABS-Chinese indicated a significant increase in the communication domain, suggesting that the intervention effectively improved communication functioning. The overall adaptive behavior composite score and socialization domain did not reach significance, but their effect sizes indicated a moderate effect on overall adaptive behavior and social functioning. The non-significance in the adaptive behavior composite score was possibly due to the inclusion of the other two subscales (daily living skills, and motor skills) irrelevant to the purpose of the intervention. The finding of significant improvement in social communication was consistent with previous studies for children with ASD (Ho et al., 2013; Lang et al., 2010; Ung et al., 2015). As emotion dysregulation in individuals ASD may be related to problems in communication (Jahromi et al., 2013, 2012; Mazefsky et al., 2013; Mazefsky \& White, 2014), improving communication could potentially facilitate the acquisition of emotion regulation. That is, it is possible that the intervention targeted skills in expressing emotions in context and seeking help which strengthened communication skills leading to the overall improvement in behavioral and emotional competence.

The statistically non-significant subscales in BERS-Chinese and VABS-Chinese (e.g., Interpersonal Strength and Socialization) may indicate these relatively weak areas in relation to the significant subscales (e.g., Intrapersonal Strength, School Functioning, and Communication) in the children's overall behavioral emotional competence. As such, the interpersonal strength and socialization require social skills in combination with others' behavior, whereas the 
intrapersonal strength, school functioning, and communication focus more on the individual's self-competence in social and school life. Rather than teaching social interaction skills, the intervention curriculum addressed self-focused emotional skills. These skills are meant to empower the students' competence though identifying the environment in relation to self and others (i.e., recognizing emotions of others and seeking help) and handling emotions within oneself (i.e., recognizing, expressing, and regulating own emotions, affirming self). Therefore, the intervention strengthened the children's overall behavioral and emotional competence in the areas related to self, such as the increased ability to handle negative emotions, participate in school activities, and communicate with others. The emphasis on self-regulation also partially explained the moderate effects yet not statistically significant areas in relating to others-focused behavior, such as interpersonal relationship, family involvement, affective strength in BERSChinese, and socialization domain in VABS-Chinese.

The results of this study indicated the CBT-based intervention with ABA teaching strategies was applicable to Chinese children with ASD. This has important implications on services provided to elementary children with ASD in China. It is important for these children to receive intervention to build their behavioral and emotional competence in order to benefit from an inclusive or general education.

\section{Strengths and Limitations}

The major strength of the current study was that it extended the literature by empirically testing the efficacy of a CBT-based intervention in Chinese children with ASD. We also used direct testing of target emotional skills as one of the outcome measures and incorporated teaching strategies derived from ABA principles to enhance acquisition of these target skills. 
Limitations of this study included a small sample size with no control group, the lack of a plan of generalization beyond the intervention, and the lack of follow-up data after the posttests. Given the weakness of the design, the results need to be interpreted with caution. We cannot rule out the potential threats of maturation, history, expectancy bias, or regression to the mean without a control group. Single subject experimental designs may be an alternative to obtain the efficacy of the intervention. The follow-up data were not available due to the scope of the study. Again, this should be incorporated in future research.

As discussed, emotion regulation is a complex domain requiring the recognition of key elements in social situations and a set of interpersonal and intrapersonal skills. Poor emotion regulation in children with ASD in social interactions, school engagement, and behaviors may be a result of the deficits in social communication and restrictive/repetitive interests and behaviors (Jahromi et al., 2013, 2012; Mazefsky et al., 2013; Mazefsky \& White, 2014). Therefore, a comprehensive intervention addressing core deficits of ASD with multiple evaluations is essential. It may be necessary to add social skills training in the intervention in order to increase the children's ability in relating to others in complex social situations (e.g., showing empathy to others after identifying their emotions in context; providing multiple alternatives for problem solving and making decision on the best alternative after emotion regulation training).

\section{Future Research}

Future research should consider the use of a single subject experimental design to validate the intervention before conducting a randomized controlled trial with a large sample. Plans for generalization from the intervention setting to real life should be considered and evaluated in future research. It is necessary to include child report measures and informants who were blind to research, such as the children's teachers. Because the services for elementary 
children with ASD is sparse in China, it may be useful to expand the impact of the intervention by training clinicians or qualified instructors to provide such an intervention for elementary students in the community or school settings. More research in professional training for intervention implementation in China is necessary.

\section{Conclusion}

Our preliminary results show promise for further evaluation of the efficacy of the intervention with a randomized controlled trial in Chinese children with ASD. The study also provides a possible answer in response to the lack of evidence-based intervention for elementary children with ASD in China. It is important to continue this line of research and extend the implementation from clinics to school or community settings in China. 


\section{Compliance with Ethical Standards}

\section{Disclosure of Potential Conflict of Interest}

All authors involved in this study do not have any interests that might be interpreted as influencing the research.

\section{Ethical Approval}

All procedures performed in studies involving human participants were in accordance with the ethical standards of the institutional and/or national research committee and with the 1964 Helsinki declaration and its later amendments or comparable ethical standards.

\section{Informed Consent}

Informed consent was obtained from all participants (teachers, children and their parents) included in the study. 


\section{References}

American Psychiatric Association. (2013). Diagnostic and statistical manual of mental disorders (DSM-5®). Washington, D. C.: Author.

Attwood, T. (2004). Cognitive behaviour therapy for children and adults with Asperger's Syndrome. Behaviour Change, 21(3), 147-161. https://doi.org/10.1375/bech.21.3.147.55995

Bauminger, N., \& Kasari, C. (2000). Loneliness and friendship in high-functioning children with autism. Child Development, 71(2), 447-456.

Bauminger, Nirit, Shulman, C., \& Agam, G. (2003). Peer interaction and loneliness in highfunctioning children with autism. Journal of Autism and Developmental Disorders, 33(5), 489-507. https://doi.org/10.1023/A:1025827427901

Camargo, S. P. H., Rispoli, M., Ganz, J., Hong, E. R., Davis, H., \& Mason, R. (2015).

Behaviorally based interventions for teaching social interaction skills to children with ASD in inclusive settings: A meta-analysis. Journal of Behavioral Education, 25(2), 223-248. https://doi.org/10.1007/s10864-015-9240-1

Carter, A. S., Volkmar, F. R., Sparrow, S. S., Jing-Jen, W., Lord, C., Dawson, G., ... Schopler, E. (1998). The Vineland Adaptive Behavior Scales: Supplementary norms for individuals with autism. Journal of Autism and Developmental Disorders, 28(4), 287-302. http://dx.doi.org.proxy2.cl.msu.edu/10.1023/A:1026056518470

Chlebowski, C., Green, J. A., Barton, M. L., \& Fein, D. (2010). Using the Childhood Autism Rating Scale to diagnose autism spectrum disorders. Journal of Autism and Developmental Disorders, 40(7), 787-799. https://doi.org/10.1007/s10803-009-0926-X 
Cohen, J. (1988). Statistical power analysis for the behavioral sciences (2nd ed). Hillsdale, N.J: L. Erlbaum Associates.

Compas, B. E., Jaser, S. S., Dunbar, J. P., Watson, K. H., Bettis, A. H., Gruhn, M. A., \& Williams, E. K. (2014). Coping and emotion regulation from childhood to early adulthood: Points of convergence and divergence. Australian Journal of Psychology, 66(2), 71-81. https://doi.org/10.1111/ajpy.12043

Epstein, M. H. (2000). The Behavioral and Emotional Rating Scale: A strength-based approach to assessment. Assessment for Effective Intervention, 25(3), 249-256. https://doi.org/10.1177/073724770002500304

Feng, H., Chou, W.-C., Sun, W.-C., \& Lee, G. T. (2014). Zibizheng ertong: shehui-qingxu jiaoyu shiwu gongzuo shouce. [Handbook of social and emotional instruction for children with autism]. Taipei, Taiwan: Psychological Publisher.

Feng, H., Lo, Y., Tsai, S., \& Cartledge, G. (2008). The effects of theory-of-mind and social skill training on the social competence of a sixth-grade student with autism. Journal of Positive Behavior Interventions, 10(4), 228-242. https://doi.org/10.1177/1098300708319906

Feng, H., \& Sun, W.-C. (2017). Tzu-pi cheng fa chan pen wei ping liang hsi tung [Developmentbased behavior assessment system for children with autism]. Taipei, Taiwan: Hua-Teng Publisher.

Gross, J. J. (2002). Emotion regulation: affective, cognitive, and social consequences. Psychophysiology, 39(3), 281-291. https://doi.org/10.1017.S0048577201393198 
Heward, W. L. (1994). Three "low-tech" strategies for increasing the frequency of active student response during group instruction. In Behavior analysis in education: Focus on measurably superior education (pp. 283-320). Pacific Grove, CA: Brooks/Cole.

Ho, B. P. V., Stephenson, J., \& Carter, M. (2013). Cognitive-behavioral approach for children with autism spectrum disorders: A meta-analysis. Review Journal of Autism and Developmental Disorders, 1(1), 18-33. https://doi.org/10.1007/s40489-013-0002-5

Huang, A. X., Jia, M., \& Wheeler, J. J. (2013). Children with autism in the People's Republic of China: Diagnosis, legal issues, and educational services. Journal of Autism and Developmental Disorders, 43(9), 1991-2001. https://doi.org/10.1007/s10803-012-1722-6

Jahromi, L. B., Bryce, C. I., \& Swanson, J. (2013). The importance of self-regulation for the school and peer engagement of children with high-functioning autism. Research in Autism Spectrum Disorders, 7(2), 235-246. https://doi.org/10.1016/j.rasd.2012.08.012

Jahromi, L. B., Meek, S. E., \& Ober-Reynolds, S. (2012). Emotion regulation in the context of frustration in children with high functioning autism and their typical peers. Journal of Child Psychology and Psychiatry, and Allied Disciplines, 53(12), 1250-1258. https://doi.org/10.1111/j.1469-7610.2012.02560.x

Lang, R., Regester, A., Lauderdale, S., Ashbaugh, K., \& Haring, A. (2010). Treatment of anxiety in autism spectrum disorders using cognitive behaviour therapy: A systematic review. Developmental Neurorehabilitation, 13(1), 53-63. https://doi.org/10.3109/17518420903236288

Li, J. H., Zhong, J. M., Cai, L. Y., Chen, Y., \& Zhou, M. Z. (2005). Er tong gu du zheng ping guliang biao de lin chuang ying yong yan jiu [The clinical applications of the Childhood Autism Rating Scale]. Zhong Guo Er Tong Bao Jian Za Zhi, 13(3), 267-268. 
Liu, J., Ma, H., He, Y.-L., Xie, B., Xu, Y.-F., Tang, H.-Y., .. YU, X. (2011). Mental health system in China: history, recent service reform and future challenges. World Psychiatry, $10(3), 210-216$.

Liu, Y. (2007). Jiāng Xī shěng 75 lì gū dú zhèng ér tóng de xiàn zhuàng diào chá [A Study on seventy-five autistic children in Jiangxi province]. Zhōng Guó Tè Shū Jiào Yù, 11, 49-54.

Lu, J. P., Yang, Z. W., Shu, M. Y., \& Su, L. Y. (2004). Er tong gu du zheng liang biao ping ding de xin du xiao du fen xi [Reliability and validity analysis of the Childhood Autism Rating Scale]. Zhong Guo Xian Dai Yi Xue Za Zhi, 14(3), 119-123.

Matson, J. L., Matson, M. L., \& Rivet, T. T. (2007). Social-skills treatments for children with autism spectrum disorders: an overview. Behavior Modification, 31(5), 682-707. https://doi.org/10.1177/0145445507301650

Mazefsky, C. A., Herrington, J., Siegel, M., Scarpa, A., Maddox, B. B., Scahill, L., \& White, S. W. (2013). The role of emotion regulation in autism spectrum disorder. Journal of the American Academy of Child and Adolescent Psychiatry, 52(7), 679-688. https://doi.org/10.1016/j.jaac.2013.05.006

Mazefsky, C. A., \& White, S. W. (2014). Emotion regulation: concepts \& practice in autism spectrum disorder. Child and Adolescent Psychiatric Clinics of North America, 23(1), 15-24. https://doi.org/10.1016/j.chc.2013.07.002

McCabe, H. (2013). Bamboo shoots after the rain: Development and challenges of autism intervention in China. Autism, 17(5), 510-526. https://doi.org/10.1177/1362361312436849 
McKay, M., Wood, J. C., \& Brantley, J. (2007). The dialectical behavior therapy skills workbook: practical DBT exercises for learning mindfulness, interpersonal effectiveness, emotion regulation \& distress tolerance. Oakland, CA: New Harbinger Publications.

Morris, S. B., \& DeShon, R. P. (2002). Combining effect size estimates in meta-analysis with repeated measures and independent-groups designs. Psychological Methods, 7(1), 105125. https://doi.org/10.1037/1082-989X.7.1.105

Moyal, N., Henik, A., \& Anholt, G. E. (2014). Cognitive strategies to regulate emotionscurrent evidence and future directions. Emotion Science, 4, 1019. https://doi.org/10.3389/fpsyg.2013.01019

National Autism Center. (2015). Findings and conclusions: National standards project phase 2. Randoph, MA: Author.

Reichow, B., \& Volkmar, F. R. (2009). Social skills Interventions for individuals with autism: Evaluation for evidence-based practices within a best evidence synthesis framework. Journal of Autism and Developmental Disorders, 40(2), 149-166. https://doi.org/10.1007/s10803-009-0842-0

Rieffe, C., Terwogt, M. M., \& Kotronopoulou, K. (2006). Awareness of single and multiple emotions in high-functioning children with autism. Journal of Autism and Developmental Disorders, 37(3), 455-465. https://doi.org/10.1007/s10803-006-0171-5

Samson, A. C., Huber, O., \& Gross, J. J. (2012). Emotion regulation in Asperger's syndrome and high-functioning autism. Emotion (Washington, D.C.), 12(4), 659-665. https://doi.org/10.1037/a0027975

Samson, A. C., Phillips, J. M., Parker, K. J., Shah, S., Gross, J. J., \& Hardan, A. Y. (2014). Emotion dysregulation and the core features of autism spectrum disorder. Journal of 
Autism and Developmental Disorders, 44(7), 1766-1772. https://doi.org/10.1007/s10803013-2022-5

Scarpa, A., \& Reyes, N. M. (2011). Improving emotion regulation with CBT in young children with high functioning autism spectrum disorders: a pilot study. Behavioural and Cognitive Psychotherapy, 39(4), 495-500. https://doi.org/10.1017/S1352465811000063

Scarpa, A., Wells, A., \& Attwood, T. (2013). Exploring feelings for young children with highfunctioning autism or Asperger's disorder: the STAMP treatment manual. London: Jessica Kingsley Publishers.

Schopler, E., Reichler, R. J., \& Renner, B. R. (2002). The childhood autism rating scale (CARS). Western Psychological Services Los Angeles.

Shenzhen Autism Society. (2013). zhōng guó zì bì zhèng rén shì fú wù xiàn zhuàng diào chá [Services for people with autism in China]. Beijing: HuaXia Publishing House.

Simonoff, E., Pickles, A., Charman, T., Chandler, S., Loucas, T., \& Baird, G. (2008). Psychiatric disorders in children with autism spectrum disorders: prevalence, comorbidity, and associated factors in a population-derived sample. Journal of the American Academy of Child and Adolescent Psychiatry, 47(8), 921-929. https://doi.org/10.1097/CHI.0b013e318179964f

Sparrow, S., S., Balla, D., A., \& Cicchetti, D., V. (1984). Vineland adaptive behavior scales (1st ed.). Circle Pines: MN: American Guidance Service.

Sun, X., Allison, C., Matthews, F. E., Sharp, S. J., Auyeung, B., Baron-Cohen, S., \& Brayne, C. (2013). Prevalence of autism in mainland China, Hong Kong and Taiwan: a systematic review and meta-analysis. Molecular Autism, 4, 7. https://doi.org/10.1186/2040-2392-4-7 
Tantam, D. (2003). The challenge of adolescents and adults with Asperger Syndrome. Child Adolecence and Psychiatric Clinics of North America, 12, 143-163.

Thomson, K., Burnham Riosa, P., \& Weiss, J. A. (2015). Brief report of preliminary outcomes of an emotion regulation intervention for children with autism spectrum disorder. Journal of Autism and Developmental Disorders, 45(11), 3487-3495. https://doi.org/10.1007/s10803-015-2446-1

Ung, D., Selles, R., Small, B. J., \& Storch, E. A. (2015). A systematic review and meta-analysis of cognitive-behavioral therapy for anxiety in youth with high-functioning autism spectrum disorders. Child Psychiatry and Human Development, 46(4), 533-547. https://doi.org/10.1007/s10578-014-0494-y

Virués-Ortega, J. (2010). Applied behavior analytic intervention for autism in early childhood: meta-analysis, meta-regression and dose-response meta-analysis of multiple outcomes. Clinical Psychology Review, 30(4), 387-399. https://doi.org/10.1016/j.cpr.2010.01.008

Wang, H., Peng, X., \& Wang, Y. (2011). Běi jīng shì hăi diàn qū xiăo xué róng hé jiào yù xiàn zhuàng diào chá yán jiū bào gào [An investigation report on the present integrated education in primary schools in Haidian District, Beijing]. Zhōng Guó Tè Shū Jiào Yù, 4, $37-41$.

Wechsler, D. (2003). Wechsler Intelligence Scale for Children® - Fourth Edition. San Antonio, TX: Psychological Corporation.

Weiss, J. A., Thomson, K., \& Chan, L. (2014). A systematic literature review of emotion regulation measurement in individuals with autism spectrum disorder. Autism Research: Official Journal of the International Society for Autism Research, 7(6), 629-648. https://doi.org/10.1002/aur.1426 
Wong, C., Odom, S. L., Hume, K. A., Cox, A. W., Fettig, A., Kucharczyk, S., ... Schultz, T. R. (2015). Evidence-based practices for children, youth, and young adults with autism spectrum disorder: A comprehensive review. Journal of Autism and Developmental Disorders, 45(7), 1951-1966. https://doi.org/10.1007/s10803-014-2351-z

Wu, W., Chang, C., Lu, T., \& Chiu, S. (2004). Wen lan shi ying hang wei liang biao. [Vineland adaptive behavior scales]. Taipei, Taiwan: Psychological Publisher.

Yang, T.-Z. (2001). Xing wei yu qing xu ping liang biao [Behavioral Emotional Rating Scale]. Taipei, Taiwan: Psychological Publisher.

Zhang, H. C. (2008). Wei shi er tong zhi li liang biao di si ban zhong wen ban [Wechsler Intelligence Scale for Children-Fourth Edition-Chinese Version]. Guangdong, Zhuhai: King-May Psychological Assessment.

Zhang, H. C. (2009). Wei shi er tong zhi li liang biao di si ban (WISC-IV) zhong wen ban de xiu ding [The revision of WISC-IV Chinese version]. Xin Li Ke Xue [Psychological Science], $32(5), 1177-1179$. 
Table1. Parent demographic information and child characteristics

\begin{tabular}{|c|c|}
\hline \multicolumn{2}{|l|}{$\mathrm{N}=8$} \\
\hline Variables & $\mathrm{N}(\%)$ \\
\hline \multicolumn{2}{|l|}{ Parent Variables } \\
\hline \begin{tabular}{|l} 
Parent Gender \\
Male \\
Female
\end{tabular} & $\begin{array}{l}2(25 \%) \\
6(75 \%)\end{array}$ \\
\hline Han Ethnicity & $8(100 \%)$ \\
\hline Parent Age Mean (SD) & $36.75(2.29)$ \\
\hline $30-39$ & $7(88 \%)$ \\
\hline $40-49$ & $1(12 \%)$ \\
\hline \multicolumn{2}{|l|}{ Parent Education } \\
\hline Less than high school & $0(0 \%)$ \\
\hline High school & $3(38 \%)$ \\
\hline Associate degree & $3(38 \%)$ \\
\hline College & $2(24 \%)$ \\
\hline \multicolumn{2}{|l|}{ Family Income (RMB) } \\
\hline $75-100 \mathrm{~K}$ & $0(0 \%)$ \\
\hline$>100 \mathrm{~K}$ & $8(100 \%)$ \\
\hline \multicolumn{2}{|l|}{ Child Variables } \\
\hline Child male gender & $7(88 \%)$ \\
\hline Child Age Mean (SD) & $7.69(0.56)$ \\
\hline $7-8$ & $6(75 \%)$ \\
\hline $8-9$ & $2(25 \%)$ \\
\hline Child IQ Mean (SD) & $90.38(19.24)$ \\
\hline $70-75$ & $3(38 \%)$ \\
\hline $76-85$ & $0(0 \%)$ \\
\hline $86-100$ & $3(38 \%)$ \\
\hline $101-120$ & $2(24 \%)$ \\
\hline CARS Mean (SD) & $31.31(1.75)$ \\
\hline 30-36 mild to moderate ASD & $8(100 \%)$ \\
\hline$>36$ severe ASD & $0(0 \%)$ \\
\hline
\end{tabular}


Table 2. An example of an "angry" scenario used to teach emotion recognition and the associated context as well as to express their own emotions with associated context. The picture was presented to the children, and the therapist followed the scripts to ask questions and solicit answers from either individual child or the group during the instruction. The therapist gave praises for correct answers and provided assistance to facilitate correct answers.

\begin{tabular}{|c|c|}
\hline Therapist & Child \\
\hline \multicolumn{2}{|l|}{ Emotion recognition } \\
\hline $\begin{array}{l}\text { Q: "How does this boy feel?" or "What is her } \\
\text { emotion?" }\end{array}$ & $\begin{array}{l}\text { A: "He is angry." or "upset." Or any reasonable } \\
\text { answer }\end{array}$ \\
\hline \multicolumn{2}{|l|}{ Emotion recognition in context } \\
\hline Q: “How does this boy feel?" & A: "He is angry." Or any reasonable answer \\
\hline $\begin{array}{l}\text { Q: "A girl broke his balloon. What has } \\
\text { happened to him?" }\end{array}$ & $\begin{array}{l}\text { A: "Someone broke his balloon." (or similar } \\
\text { descriptions) }\end{array}$ \\
\hline Q: "How does he feel?" & A: "He is angry." \\
\hline Q: "Why he feels angry?" & A: "Because someone broke his balloon." \\
\hline \multicolumn{2}{|l|}{ Expressing own emotions in context } \\
\hline $\begin{array}{l}\text { Q: "This boy is (child's name). Someone broke } \\
\text { your toy balloon. What happened to you?" }\end{array}$ & $\begin{array}{l}\text { A: "My balloon is broken." (or similar } \\
\text { descriptions) }\end{array}$ \\
\hline Q: "How do you feel?" & A: I feel angry.” \\
\hline Q: Why you feel angry?" & A:"Because my balloon is broken." \\
\hline
\end{tabular}

Note. Adopted from Feng, Chou, Sun, \& Lee (2014). Used with permission from the publisher. 
Table 3. An example of a scenario used for children to practice how to seek help in a difficult situation. The picture was presented to the children, and the therapist followed the scripts to ask questions and solicit answers from either individual child or the group during the instruction. The therapist gave praises for correct answers and provided assistance to facilitate correct answers or self-affirmation.

\begin{tabular}{|c|c|}
\hline \multicolumn{2}{|l|}{\begin{tabular}{|l|} 
Seeking help \\
\end{tabular}} \\
\hline Therapist & Child \\
\hline Q: “What happened?" & $\begin{array}{l}\text { A: "His remote control airplane is stuck." (or } \\
\text { similar descriptions) }\end{array}$ \\
\hline $\begin{array}{l}\text { Q: "What can he do to solve this problem?" or } \\
\text { "Do you have any solutions for him?" }\end{array}$ & $\begin{array}{l}\text { A: "He needs to ask a grown-up for help." (or } \\
\text { any reasonable solutions) }\end{array}$ \\
\hline \multicolumn{2}{|l|}{ Emotion regulation } \\
\hline $\begin{array}{l}\text { Q: "This boy is (child's name). Your remote } \\
\text { airplane is stuck. How do you feel?" }\end{array}$ & A: "I feel upset (or any reasonable answer)" \\
\hline Q: Why do you feel upset? & A: "Because my airplane is stuck." \\
\hline $\begin{array}{l}\text { Q: Ask yourself, "What can I do to feel better } \\
\text { and not get upset?" }\end{array}$ & $\begin{array}{l}\text { A: "I can ask my mom to help." or "I can count } \\
\text { backwards" or "breathe deeply." }\end{array}$ \\
\hline Q: "What can you say to yourself?" & $\begin{array}{l}\text { A: "It's ok. I am still learning. I am smart." (or } \\
\text { any positive self affirmation.) }\end{array}$ \\
\hline
\end{tabular}

Note. Scenarios for emotion regulation used in individual sessions were individualized for each child with role play without presenting pictures. Adopted from Feng, Chou, Sun, \& Lee (2014). Used with permission from the publisher. 
Table 4. Descriptives, mean (SD) and change of BERS-Chinese and VABS-Chinese scores from pretest to posttest

\begin{tabular}{|l|l|l|l|l|l|l|}
\hline & $\begin{array}{l}\text { Pre-test } \\
\mathrm{M}(\mathrm{SD})\end{array}$ & $\begin{array}{l}\text { Post-test } \\
\mathrm{M}(\mathrm{SD})\end{array}$ & $z$ & $p$ & $r$ & Cohen's $d$ \\
\hline BERS-Chinese (n) & 8 & 8 & & & & \\
\hline Age & $7.69(0.56)$ & $8.06(0.55)$ & & & & \\
\hline Interpersonal Strength & $7(1.69)$ & $8(2.51)$ & -.95 & .34 & .36 & .42 \\
\hline Family Involvement & $9.25(1.39)$ & $10.75(1.39)$ & -1.69 & .09 & -.21 & .69 \\
\hline Intrapersonal Strength & $7.13(1.55)$ & $9.13(1.64)$ & -2.01 & $.04^{*}$ & .36 & 1.11 \\
\hline School Functioning & $7.88(1.25)$ & $9.25(1.49)$ & -2.23 & $.03^{*}$ & .71 & 1.31 \\
\hline Affective Strength & $9.50(2.14)$ & $11.13(2.23)$ & -1.48 & .14 & .18 & .58 \\
\hline Total Strength Index & $40.75(5.37)$ & $48.25(6.76)$ & -2.10 & $.04 *$ & .17 & .96 \\
\hline VABS-Chinese (n) & 8 & 8 & & & & \\
\hline Communication & $83.38(13.82)$ & $93.75(19.32)$ & -.2 .37 & $.02^{*}$ & .83 & 1.07 \\
\hline Daily Living Skills & $75.00(14.07)$ & $81.38(18.27)$ & -.77 & .44 & .65 & .47 \\
\hline Socialization & $75.63(14.62)$ & $84.13(20.07)$ & -1.61 & .11 & .62 & .56 \\
\hline Motor Skills & $85.25(10.87)$ & $89.13(14.33)$ & -1.16 & .25 & .77 & .45 \\
\hline Total Score & $75.25(14.26)$ & $83.25(17.43)$ & -1.58 & .12 & .68 & .63 \\
\hline
\end{tabular}

Note. BERS-Chinese: Behavior and Emotional Rating Scale-Chinese version; VABS-Chinese Vineland Adaptive Behavior Scale-Chinese version; Scores reported in T-scores; r r pretest-posttest Spearman's rho; * $p \leq .05$, Cohen's $d: 0.2$ small effect, 0.5 moderate effect, 0.8 large effect. 